\title{
QUALITY OF LIFE OF CHRONIC KIDNEY DISEASE PATIENTS WITH ROUTINE HEMODIALYSIS IN GENERAL HOSPITALS IN SLEMAN YOGYAKARTA
}

\author{
SIHOMBING J. ${ }^{1}$, HAKIM L. ${ }^{1}$, ANDAYANI T. M. ${ }^{1}$, IRIJANTO F. ${ }^{2}$ \\ ${ }^{1}$ Faculty of Pharmacy, Gadjah Mada University, Yogyakarta, Indonesia, ${ }^{2}$ Hemodialysis Department Gadjah Mada University Academic \\ Hospital, Yogyakarta, Indonesia \\ Email: jhonson.sihombing@yahoo.com \\ Received: 24 Oct 2016 Revised and Accepted: 21 Dec 2016
}

\begin{abstract}
Objective: To elicit quality of life (QOL) of chronic kidney disease (CKD) patients with routine hemodialysis receiving erythropoietin, to compare the QOL of CKD patients with routine hemodialysis receiving different erythropoietin, and to explore the change in QOL over six months for patients managed in the hospitals.
\end{abstract}

Methods: A multicenter prospective study was conducted among adult CKD patients in Yogyakarta. QOL was measured using kidney disease quality of life-short form (KDQOL-SFTM) questionnaire and a FACIT fatigue scale questionnaire. CKD patients were divided into 2 groups: those receiving erythropoietin alpha $(n=74)$ and those receiving erythropoietin beta $(n=39)$. Both groups were asked to complete the KDQOL-SFTM questionnaire and a FACIT fatigue scale questionnaire two times in six months range.

Results: In the first period, the average rate of the KDQOL-SF and FACIT for CKD patients receive erythropoietin alpha compared to CKD patients receive erythropoietin beta was 77.24: 80.21 and 3.35: 3.49 while in the second period, the average rate of the KDQOL-SF and FACIT for CKD patients receive erythropoietin alpha compared to CKD patients receive erythropoietin beta was 80.45: 83.95 and 3.45: 3.56.

Conclusion: Erythropoietin can improve QOL of CKD patients with routine hemodialysis, while erythropoietin beta gives more improvement, but statistically, it doesn't different significantly.

Keywords: CKD, Hemodialysis, QOL, Erythropoietin

(C) 2017 The Authors. Published by Innovare Academic Sciences Pvt Ltd. This is an open access article under the CC BY license (http://creativecommons.org/licenses/by/4. 0/] DOI: http://dx.doi.org/10.22159/ijpps.2017v9i2.15844

\section{INTRODUCTION}

CKD prevalence in all over the world predicted to reach $8-16 \%$ of the populations. CKD incidence rises every year, especially in developing countries cause of increasing life expectation age, so that people have a longer age. CKD therapy needs special treatment such as dialysis (hemodialysis or peritoneal dialysis) or renal transplantation which needs a lot of costs. Renal transplantation actually is more efficient compared to dialysis because only in one treatment can make patients avoid dialysis procedure which takes place in relatively long duration. Meanwhile, many people use dialysis to treat CKD [1].

One of CKD complication is anemia. Anemia is common in CKD patients, especially if the glomerular filtration rate $(\mathrm{GFR})<60$ $\mathrm{ml} / \mathrm{min}$ and almost all CKD patients have anemia if GFR $<27 \mathrm{ml} / \mathrm{min}$. It also said that almost 50\% CKD stage 3-4 patients have anemia and increase almost 75\% in end-stage renal disease (ESRD) [2].

Anemia in CKD is most of the decrease erythropoietin (EPO) production, but can also because of inadequate of blood iron, inadequate of nutrition, inflammation, hyper parathyroid, excessive loss of blood, etc. Non-treated anemia can make fatigue, decrease the ability of physical activity, cognitive function, immune response and decrease the quality of life that can increase morbidity and mortality [3]

Anemia of EPO deficiency can be treated by EPO delivery, red cell transfusion or both. Most of that is with EPO delivery. The earlier research said that EPO delivery can decrease transfusion and increase patient's QOL compared with non-delivery EPO [4]. Another study reported that the total cost of anemia treatment in CKD patients with hemodialysis is cheaper with transfusion compared with EPO delivery, but patient's QOL is better with EPO delivery compared with transfusion [5].
Erythropoietin is an essential growth factor for erythroid progenitor cells, which produced mainly in the kidney [6]. Short-acting erythropoietin-stimulating agents (ESAs) that have been used for the treatment of renal anemia, such as erythropoietin alpha and erythropoietin beta have a half-life of $6-8 \mathrm{~h}$ when given intravenously and a half-life of 19-24 h when given subcutaneously, but more effective when administered subcutaneously. Long-acting ESAs such as darbepoetin alpha and CERA have a half-life 2-3 times than short-acting ESAs. In Indonesia, there are only short-acting ESAs used for the treatment of renal anemia.

WHO defines the QOL as a multiple dimensions concept that concerns an individual's usual or expected physical, emotional and social well-being. It will describe the design, assessment, analysis and interpretation of single and multi-item, subjective measurement scales. The broad definition will include scales or instruments that ask general questions, such as "in general, how would you rate your health now?", and more specific questions on particular symptoms and side effects, such as "during the past week have you felt nauseated?" This measurement scales all have the common feature of using a standardised approach to assessing a person's perception of their own health by using the numerical scoring system and may include one or several dimensions of QOL [7].

There are some instruments to measure fatigue scale. One of them is Functional Assessment Chronic Illness Therapy (FACIT) Fatigue Scale which was validated by Cella, et al. (2005) [8]. It said that the FACIT-Fatigue Scale is a brief, valid measure for monitoring important symptom and its effects of chronic illness. FACIT-Fatigue Scale consists of thirteen questions and easy to use to measure individual fatigue scale during their daily activities in last one week [9]. FACIT-Fatigue Scale is a collection of health-related quality of life questionnaires targeted to the management of chronic illness by measuring functional body system [10]. This makes us know the relation of fatigue with QOL. 


\section{MATERIALS AND METHODS}

\section{Methods}

We conducted a prospective study of CKD patients with routine hemodialysis from 3 big hospitals in Yogyakarta from May 2015March 2016. Participants were eligible if they were CKD patients with routine hemodialysis at least in three months, aged from 20-80 $y$ and use EPO to treat their anemia. Participants with a current functioning kidney transplant or diagnosed with cancer were excluded. Using a patient database, we used purposive sampling to capture a range of demographic and clinical characteristics, including age, gender, ethnicity, work status, employment, comorbid, and kind of EPO used.

Ethical approval was obtained from medical and health research ethics committee (MHREC) faculty of medicine Gadjah Mada University with reference number KE/FK5/6/EC/2015. Patients' approvals were obtained by using informed consent forms. The surveys were administrated face to face and participants can answer the questions his/herself or with their family.

Sociodemographic and clinical information were collected from patient's medical records. The participants were asked to value their current health using KDQOL-SF and FACIT-Fatigue scale. They were asked to rate their health where QOL was measured on a scale from 0 (least preferred health state) to 100 (perfect health with no kidney disease). They were also asked to rate their fatigue scale from 0 (fatigue very much) to 4 (not fatigue at all). Participants then completed the FACIT-Fatigue scale and KDQOL-SF questionnaire, a multidimensional, a reliable and validated instrument developed for dialysis patients. They completed the questionnaire two times in approximate six-month range. The KDQOL includes the SF-36 health survey as its generic core measuring eight domains such as physical functioning, role limitation physical, role limitation emotional health, energy (vitality), emotional well-being, social functioning, pain, and general health perception; augmented with multi-scale targeted at CKD-specific concerns (symptoms and problems, effect of kidney disease, burden of kidney disease, work status, cognitive function, quality of social interaction, sexual function, sleep, social support and dialysis staff). Descriptive statistics were calculated and reported as a mean \pm standard deviation (SD). Then compare the mean of two groups (patients receive erythropoietin alpha with patients receive erythropoietin beta) by independent sample t-test. The analysis was conducted using statistical package for social science (SPSS) 16 version.

\section{RESULTS}

One hundred and thirteen CKD patients with routine hemodialysis from May 2015 to March 2016 provided baseline data (table 1). More than $50 \%$ of patients were male. The mean patient age was $40-60$ y and more than $90 \%$ were Javanese.

The results of the FACIT-fatigue scale questionnaire in CKD patients with routine hemodialysis $(n=113)$ were listed in table 2 . In the first period, the average rate of FACIT for CKD patients receives erythropoietin alpha compared to CKD patients receive erythropoietin beta was 3.35: 3.49 while in the second period (six months later), the average rate of FACIT for CKD patients receives erythropoietin alpha compared to CKD patients receive erythropoietin beta was 3.45: 3.56. Statistic calculation of rate of FACIT shown that compare mean of two groups (patients receive erythropoietin alpha with patients receive erythropoietin beta) was not different significantly (even in the first period or at the second period) except at question no An16 (I have to limit my social activity because I am tired), respectively $(2.97 \pm 1.34$ vs $3.69 \pm 0.83[\mathrm{P}<0.05]$ at the first period and $2.85 \pm 1.58$ vs $3.56 \pm 1.02[\mathrm{P}<0.05]$ at the second period).

The results of the KDQOL-SF questionnaire in CKD patients with routine hemodialysis $(n=113)$ were listed in table 3 . In the first period, the average rate of the KDQOL-SF for CKD patients receive erythropoietin alpha compared to CKD patients receive erythropoietin beta was 77.24: 80.21 while in the second period (six months later), the average rate of the KDQOL-SF for CKD patients receive erythropoietin alpha compared to CKD patients receive erythropoietin beta was 80.45: 83.95. Statistic calculation of the rate of the KDQOL-SF has shown that compare mean of two groups (patients receive erythropoietin alpha with patients receive erythropoietin beta) was not different significantly in the first period and was not different significantly in the second period, except at no A3 (Burden of kidney disease), respectively $(80.41 \pm 21.95$ vs $89.58 \pm 17.11 \quad[\mathrm{P}<0.05])$ and $\mathrm{B} 1 \quad$ (Physical functioning), respectively $(73.38 \pm 19.64$ vs $82.44 \pm 13.47[\mathrm{P}<0.05])$.

Table 1: Characteristic CKD patients with routine hemodialysis using EPO- $\alpha$ and EPO- $\beta$

\begin{tabular}{lll}
\hline Parameter & EPO- $\boldsymbol{\alpha}(\mathbf{n}=\mathbf{7 4})$ & EPO- $\boldsymbol{\beta}(\mathbf{n}=\mathbf{3 9})$ \\
\hline Age (years) & & \\
$20-40$ & 16 & 14 \\
$40-60$ & 39 & 17 \\
$>60$ & 21 & 6 \\
Gender & & 18 \\
Male & 42 & 19 \\
Female & 34 & \\
Ethnic & & 36 \\
Javanese & 72 & 1 \\
Others & 4 & 28 \\
Status & & 9 \\
Married & 68 & \\
Unmarried & 8 & 18 \\
Employment & & \\
Work & 32 & 32 \\
Not work & 44 & 5 \\
Co-morbid & & \\
HT & 56 & \\
HT, DM & 20 & \\
\hline
\end{tabular}

HT: Hypertension, DM: Diabetes Mellitus

Table 2: Results of FACIT fatigue scale questionnaire in CKD patients with routine hemodialysis

\begin{tabular}{|c|c|c|c|c|c|}
\hline \multirow[t]{2}{*}{ No } & \multirow[t]{2}{*}{ Statement } & \multicolumn{2}{|l|}{ I } & \multicolumn{2}{|l|}{ II } \\
\hline & & EPO- $\alpha$ & EPO- $\beta$ & EPO- $\alpha$ & EPO- $\beta$ \\
\hline HI7 & I feel fatigued & $3.64 \pm 0.69$ & $3.69 \pm 0.73$ & $3.89 \pm 0.35$ & $3.87 \pm 0.52$ \\
\hline HI12 & I feel weak all over & $3.61 \pm 0.72$ & $3.67 \pm 0.74$ & $3.86 \pm 0.42$ & $3.92 \pm 0.35$ \\
\hline An1 & I feel listless (washed out) & $3.65 \pm 0.69$ & $3.62 \pm 0.85$ & $3.78 \pm 0.50$ & $3.85 \pm 0.43$ \\
\hline An2 & I feel tired & $3.65 \pm 0.69$ & $3.59 \pm 0.75$ & $3.65 \pm 0.61$ & $3.62 \pm 0.67$ \\
\hline An3 & I have trouble starting things because I am tired & $3.70 \pm 0.72$ & $3.77 \pm 0.84$ & $3.97 \pm 0.16$ & $3.90 \pm 0.38$ \\
\hline An 4 & I have trouble finishing things because I am tired & $3.72 \pm 0.71$ & $3.74 \pm 0.85$ & $3.99 \pm 0.12$ & $3.92 \pm 0.35$ \\
\hline An5 & I have energy & $2.49 \pm 0.88$ & $2.64 \pm 0.58$ & $2.69 \pm 0.49$ & $2.82 \pm 0.39$ \\
\hline An7 & I am able to do my usual activities & $2.27 \pm 1.13$ & $2.62 \pm 0.99$ & $2.70 \pm 0.49$ & $2.79 \pm 0.41$ \\
\hline An8 & I need to sleep during the day & $2.51 \pm 1.21$ & $2.77 \pm 1.31$ & $1.82 \pm 1.48$ & $2.13 \pm 1.32$ \\
\hline An12 & I am too tired to eat & $3.96 \pm 0.20$ & $3.97 \pm 0.16$ & $3.99 \pm 0.12$ & $3.97 \pm 0.16$ \\
\hline An14 & I need help doing my usual activities & $3.65 \pm 0.82$ & $3.72 \pm 0.79$ & $3.91 \pm 0.50$ & $3.92 \pm 0.35$ \\
\hline An15 & I am frustrated by being too tired to do the things I want to do & $3.78 \pm 0.63$ & $3.90 \pm 0.31$ & $3.80 \pm 0.68$ & $3.95 \pm 0.32$ \\
\hline An16 & I have to limit my social activity because I am tired & $2.97 \pm 1.34$ & $3.69 \pm 0.83$ & $2.85 \pm 1.58$ & $3.56 \pm 1.02$ \\
\hline
\end{tabular}

Mean+SD, EPO- $\alpha(n=74)$, EPO- $\beta(n=39)$ 
Table 3: Results of KDQOL questionnaire in CKD patients with routine hemodialysis

\begin{tabular}{|c|c|c|c|c|c|}
\hline \multirow[t]{2}{*}{ No } & \multirow[t]{2}{*}{ Domain } & \multicolumn{2}{|l|}{ I } & \multicolumn{2}{|l|}{ II } \\
\hline & & EPO- $\alpha$ & EPO- $\beta$ & EPO- $\alpha$ & EPO- $\beta$ \\
\hline & \multicolumn{5}{|l|}{ CKD-targeted } \\
\hline A1 & Symptom/problem & $93.36 \pm 8.11$ & $90.97 \pm 9.86$ & $95.75 \pm 5.32$ & $96.21 \pm 5.12$ \\
\hline $\mathrm{A} 2$ & Effect of kidney disease & $90.42 \pm 10.03$ & $90.03 \pm 10.92$ & $94.47 \pm 6.35$ & $94.63 \pm 5.50$ \\
\hline A3 & Burden of kidney disease & $65.46 \pm 30.41$ & $67.79 \pm 27.15$ & $80.41 \pm 21.95$ & $89.58 \pm 17.11$ \\
\hline A4 & Work status & $55.41 \pm 50.05$ & $66.67 \pm 47.76$ & $36.49 \pm 48.47$ & $46.15 \pm 50.50$ \\
\hline A5 & Cognitive function & $82.88 \pm 20.11$ & $86.50 \pm 18.51$ & $89.01 \pm 12.26$ & $89.57 \pm 9.15$ \\
\hline A6 & Quality of social interaction & $89.82 \pm 12.40$ & $89.91 \pm 16.32$ & $91.89 \pm 4.17$ & $92.82 \pm 2.36$ \\
\hline A7 & Sexual function & $41.72 \pm 47.87$ & $51.60 \pm 49.02$ & $41.89 \pm 48.63$ & $55.13 \pm 49.73$ \\
\hline A8 & Sleep & $75.03 \pm 19.93$ & $77.95 \pm 16.62$ & $77.84 \pm 14.12$ & $80.51 \pm 14.99$ \\
\hline A9 & Social support & $98.89 \pm 5.68$ & $98.31 \pm 7.37$ & $98.22 \pm 7.51$ & $99.15 \pm 5.28$ \\
\hline A10 & Dialysis staff encouragement & $96.45 \pm 10.45$ & $97.44 \pm 7.13$ & $99.16 \pm 4.31$ & $99.04 \pm 4.43$ \\
\hline \multirow[t]{2}{*}{ A11 } & Patient satisfaction & $52.74 \pm 6.85$ & $55.23 \pm 7.95$ & $50.46 \pm 2.78$ & $51.72 \pm 5.15$ \\
\hline & \multicolumn{5}{|l|}{ 36-item health survey } \\
\hline B1 & Physical functioning & $67.91 \pm 24.13$ & $76.03 \pm 19.87$ & $73.38 \pm 19.64$ & $82.44 \pm 13.47$ \\
\hline B2 & Role-physical & $62.50 \pm 37.76$ & $68.59 \pm 29.09$ & $66.72 \pm 23.25$ & $75.00 \pm 25.65$ \\
\hline B3 & Pain & $88.14 \pm 23.22$ & $90.38 \pm 17.37$ & $79.63 \pm 27.01$ & $83.33 \pm 25.13$ \\
\hline B4 & General health perceptions & $73.72 \pm 16.24$ & $76.67 \pm 17.26$ & $82.09 \pm 12.05$ & $85.64 \pm 8.21$ \\
\hline B5 & Emotional well-being & $87.84 \pm 11.44$ & $88.92 \pm 10.56$ & $90.22 \pm 4.40$ & $90.46 \pm 3.96$ \\
\hline B6 & Role-emotional & $77.48 \pm 36.23$ & $76.92 \pm 34.33$ & $95.95 \pm 10.97$ & $94.87 \pm 12.18$ \\
\hline B7 & Social function & $84.80 \pm 23.16$ & $90.38 \pm 17.78$ & $95.44 \pm 12.85$ & $96.79 \pm 16.15$ \\
\hline B8 & Energy (Vitality) & $82.92 \pm 11.69$ & $82.69 \pm 13.32$ & $89.46 \pm 7.38$ & $92.05 \pm 6.04$ \\
\hline
\end{tabular}

Mean+SD, EPO- $\alpha(n=74), E P O-\beta(n=39)$

\section{DISCUSSION}

A study about correction of anemia in CKD patients receives erythropoietin alpha reported that there was improvement QOL from baseline values weather in the high hemoglobin group and in the low hemoglobin group. It also showed a similar level of improvement from baseline values in both groups, except for the score for emotional role subscale of SF-36, which was significantly higher in the low hemoglobin group [11]. Other publications deliver such a better QOL due to anemia management with erythropoietin, except for two domains regards to the ability to work (work status: 34.7 become 31.7) and role limitation caused by a physical health problem (role physical: 39.7 become 39) [12]. In this study, we also found out that six months from baseline after receiving erythropoietin alpha or beta, CKD patients had better QOL almost in all domains, except in work status from 55.41 became 36.49 for erythropoietin alpha and from 66.67 became 46.15 for erythropoietin beta.

Compared to the population with end-stage renal disease (ESRD) in other countries, our data showed better scores almost in all domains as shown in fig. 1. Compared to US dialysis patients [13], Poland dialysis patients [14], and Singapore dialysis patients [15], our data showed a poor score only in sexual function. The different rate of QOL in hemodialysis patients influenced by some factors such as race [16], change in kidney function [17], stage of anemia [11], etc.

A previous publication reported that fatigue impacts patients' abilities to manage their daily activities and to remember and concentrate on conversations and what is going on around them [18] and feel isolated from others and society [19]. This makes decreasing their participation in even simple physical and mental activities for patients on dialysis. The physical domain was highly affected in CKD patients with hemodialysis [20].

Post-dialysis fatigue patients required almost five hours of sleep to recover and had more depression, insomnia, and body aches than those who did not [21]. They also had a limitation in their functional independence and participation in social activities [22]. Research suggests that fatigue may be part of a symptom complex that includes nausea, muscle cramps, and headache, which may be the result of the fluid shifts that occur during hemodialysis [23].

Another study in China that determined same inclusive criteria with this study such as receiving routine hemodialysis for at least three months, being identified as an outpatient, $18 \mathrm{y}$ of age or older and willing to participate and sign written informed consent, gave a total score of the FACIT-fatigue scale 41 (average 3.15) [24]. It was not too different with the rate of this study that gives an average score of FACIT 3.36 for patients receive erythropoietin alpha and 3.49 for patients receive erythropoietin beta.

Our study has several other limitations that need to be considered. First, it was an observational study that we can't take part in patients' therapy, anemia management and patients' habit in their daily activity. Another one was hospital capacity of hemodialysis machines that influence on a number of hemodialysis patients.

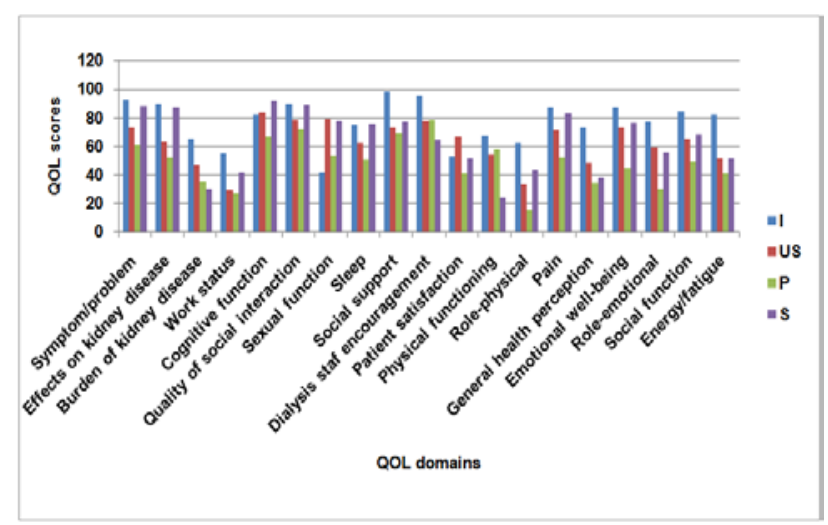

Fig. 1: Dialysis patients' quality of life scores in Indonesia, United States of America, poland and Singapore

\section{CONCLUSION}

Erythropoietin can improve the QOL of CKD patients with routine hemodialysis, while erythropoietin beta gives more improvement. CKD patients with routine hemodialysis using erythropoietin beta shown better QOL compared to CKD patients using erythropoietin alpha but overall they don't different significantly.

\section{CONFLICT OF INTERESTS}

All authors declare that they have no conflict of interest.

\section{REFERENCES}

1. Jha V, Garcia-Garcia G, Iseki K, Li Z, Naicker S, Plattner B, et al. Chronic kidney disease: global dimension and perspectives. Lancet 2013;382:260-72. 
2. Somvanshi S, Khan NZ, Ahmad M. Anemia in chronic kidney disease patients. Clin Queries: Nephrol 2012;I:198-204.

3. Lu WX, Jones-Burton C, Zhan M, Salzberg DJ, Moore J Jr, Fink JC. Survival benefit of recombinant human erythropoietin administration prior the onset of end-stage renal disease: variations across surrogates for quality of care and time. Nephron Clin Pract 2005;101:79-86.

4. Levin NW, Lazarus JM, Nissenson AR. National cooperative rHu erythropoietin study in patients with chronic renal failure-an interim report. The national cooperative rHu erythropoietin study group. Am J Kidney Dis 1993;22:3-12.

5. Naci H, Lissovoy G, Hollenbeak C, Custer B, Hofmann A, McClellan $\mathrm{W}$, et al. Historical clinical and economic consequence of anemia management in patients with end-stage renal disease on dialysis using erythropoietin stimulating agents versus routine blood transfusions: a retrospective costeffectiveness analysis. J Med Econ 2012;15:293-304.

6. Jelkmann W. Molecular biology of erythropoietin. Intern Med 2004;43:649-59.

7. Walters SJ. The quality of life outcomes in clinical trials and health-care evaluation: a practical guide to analysis and interpretation. John Wiley and Sons Ltd pub; 2009.

8. Cella D, Yount S, Sorensen M, Chartash E, Sengupta N, Grober J. Validation of the functional assessment of chronic illness therapy-fatigue scale relative to other instrumentation in patients with rheumatoid arthritis. J Rheumatol 2005;32:811-9.

9. Webster K, Cella D, Yost K. The functional assessment of chronic illness therapy (FACIT) measurement system; properties, applications, and interpretation. Health Qual Life Outcomes 2003;1:1-7.

10. Tennant KF. Assessment of fatigue in older adults: the FACITfatigue scale (Version 4). General assessment series from The Hartford Institute for Geriatric Nursing, New York, College of Nursing; 2012;20:1-2.

11. Singh AK, Szczech L, Tang KL, Barnhart H, Sapp S, Wolfson M, et al. Correction of anemia with epoetin alfa in chronic kidney disease. N Engl J Med 2006;355:2085-98.

12. Hansen RA, Chin H, Blalock S, Joy MS. Predialysis chronic kidney disease: evaluation of the quality of life in clinic patients receiving comprehensive anemia care. Res Social Administrative Pharm 2009;5:143-53.

13. Fukuhara S, Lopes AA, Bragg-Gresham JL, Kurokawa K, Mapes DL, Akizawa T, et al. the Health-related quality of life among dialysis patients on three continents: the dialysis outcomes and practice patterns study. Kidney Int 2003;64:1903-10.
14. Kostro JZ, Hellmann A, Kobiela J, Skora I, LichodziejewskaNiemierko M, Debska-Slizien A, et al. Quality of life after kidney transplantation: a prospective study. Transplant Proc 2016;48:50-4.

15. Cheung YB, Seow YY, Qu LM, Yee ACP. Measurement properties of the Chinese version of kidney disease quality of life short form (KDQOL-SFTM) in end-stage renal disease patients with poor prognosis in singapore. J Pain Symptom Manage 2012;44:923-32.

16. Unruh M, Miskulin D, Yan G, Hays RD, Benz R, Kusek JW, et al. Racial differences in health-related quality of life among hemodialysis patients. Kidney Int 2004;65:1482-91.

17. Perlman RL, Finkelstein FO, Liu L, Roys E, Kiser M, Eisele G, et al. Quality of life in chronic kidney disease (CKD): a crosssectional analysis in the renal research institute CKD study. Am J Kidney Dis 2005;45:658-66.

18. Lee BO, Lin CC, Chaboyer W, Chiang C-L, Hung CC. The fatigue experiences of hemodialysis patients in Taiwan. J Clin Nurs 2007;16:407-13.

19. Kazemi M, Nasrabadi AN, Hasanpour M, Hassankhani H, Mills J. Experience of Iranian persons receiving hemodialysis: a descriptive, exploratory study. Nurs Health Sci 2011;13:88-93.

20. Murali R, Sathyanarayana D, Muthusethupathy MA. Assessment of quality of life in chronic kidney disease patients using the kidney disease quality of life short form ${ }^{\mathrm{TM}}$ questionnaire in the Indian population: a community-based study. Asian J Pharm Clin Res 2015;8:271-4.

21. Sklar AH, Riesenberg LA, Silber AK, Ahmed W, Ali A. Post dialysis fatigue. Am J Kidney Dis 1996;28:732-6.

22. Rocco DG, Mercieri A, Yavuzer G. Multidimensional health status assessment of chronic hemodialysis patients: the impact of quality of life. Eur Medicophys 2006;42:113-9.

23. Sklar AH, Newman N, Scott R, Semenyuk L, Schultz J, Fiacco V. Identification of factor responsible for post dialysis fatigue. Am J Kidney Dis 1999;34:464-70.

24. Wang SY, Zang XY, Liu JD, Gao $M$, Cheng $M$, Zhao Y. Psychometric properties of the functional assessment of chronic illness therapy-fatigue (FACIT-Fatigue) in Chinese patients receiving maintenance dialysis. J Pain Symptom Management 2015;49:135-42.

\section{How to cite this article}

- $\quad$ Sihombing J, Hakim L, Andayani TM, Irijanto F. Quality of life of chronic kidney disease patients with routine hemodialysis in general hospitals in sleman yogyakarta. Int J Pharm Pharm Sci 2017;9(2):213-216. 